\title{
Description of Epidemiological Features, Symptoms and Mortality of the Patients with COVID-19 in Some Provinces of Iran
}

Fatemeh Khosravi Shadmani, PhD ${ }^{1 *}$; Alireza Amanollahi, PhD ${ }^{2 *}$; Alireza Zali, MD; Farid Najafi, MD, PhD'; Manoochehr Karami, PhD $^{2,4}$; Ghobad Moradi, MD, PhD ${ }^{5}$; Abdollah Mohammadian-Hafshejani, PhD ${ }^{6,7}$; Ali Ahmadi, PhD ${ }^{6,7}$; Majid Sartipi, PhD ${ }^{8}$; Masoud Shojaeian, MSc ${ }^{9}$; Elham Noori, MSc ${ }^{10}$; Masoumeh Javaheri, MSc ${ }^{9}$; Ayad Bahadorimonfared, MD, PhD ${ }^{11}$; Seyed-Saeed HashemiNazari, MD, PhD ${ }^{12^{*}}$

'Research Center for Environmental Determinants of Health (RCEDH), Health Institute, Kermanshah University of Medical Sciences, Kermanshah, Iran

${ }^{2}$ Department of Epidemiology, School of Public Health and Safety, Shahid Beheshti University of Medical Sciences, Tehran, Iran ${ }^{3}$ Department of Neurosurgery, School of Medicine, Shahid Beheshti University of Medical Sciences, Tehran, Iran ${ }^{4}$ Department of Epidemiology, School of Public Health, Hamadan University of Medical Sciences, Hamadan, Iran ${ }^{5}$ Social Determinants of Health Research Center, Research Institute for Health Development, Kurdistan University of Medical Sciences, Sanandaj, Iran

${ }^{6}$ Department of Epidemiology and Biostatistics, School of Health, Shahrekord University of Medical Sciences, Shahrekord, Iran ${ }^{7}$ Modeling in Health Research center, Shahrekord University of Medical Sciences, Shahrekord, Iran

${ }^{8}$ Health Promotion Research Centre, School of Public Health, Zahedan University of Medical Sciences, Zahedan, Iran

${ }^{9}$ Deputy of Health, Hamadan University of Medical Sciences, Hamadan, Iran

${ }^{10}$ Department of Epidemiology and Biostatistics, Kurdistan University of Medical Science, Sanandaj, Iran

${ }^{11}$ Department of Health \& Community Medicine, Faculty of Medicine, Shahid Beheshti University of Medical Sciences, Tehran, Iran ${ }^{12}$ Prevention of Cardiovascular Disease Research Center, Department of Epidemiology, School of Public Health and Safety, Shahid Beheshti University of Medical Sciences, Tehran, Iran

\begin{abstract}
Background: Clinical manifestations of COVID-19 are different. There are some risk factors for COVID-19. This study aimed to describe the epidemiological features, symptoms and mortality of the patients with COVID-19 in Iran.

Methods: This were a cohort study performed on 103,179 patients with COVID-19. The demographic and clinical data were collected in selected provinces. The required data of all patients was extracted from the COVID registry system and analyzed using STATA version 14 and Excel 2016.

Results: The mean age was 52.40 years for men and 52.41 years for women. About $55.2 \%$ of the study population were male and $44.8 \%$ were female. Totally, 60.9\% (5085) of deaths happened in men and 39.1\% (3263) in women. The mean time from onset of symptoms to hospitalization in men and women were 3.47 and 3.48 days, respectively. The mean time from onset of symptoms to isolation was 2.81 days in men and was 2.87 days in women, from onset of symptoms to death was 9.29 and 9.54 days, respectively, from onset of symptoms to discharge was 7.47 and 7.39 days, and from hospitalization to death was 6.76 and 7.05 days. Cough and shortness of breath were the most common symptoms in the patients.

Conclusion: According to the results, the overall mortality rate was higher in men than women. Women with cardiovascular disease and diabetes were more likely to die. The mean time from onset of symptoms to hospitalization, isolation, and discharge was similar in men and women.

Keywords: COVID-19, Epidemics, Iran, Mortality, Symptom

Cite this article as: Khosravi Shadmani F, Amanollahi A, Zali A, Najafi F, Karami M, Moradi G, et al. Description of epidemiological features, symptoms and mortality of the patients with COVID-19 in some provinces of iran. Arch Iran Med. 2021;24(10):733-740. doi: 10.34172/aim.2021.108
\end{abstract}

Received: April 8, 2021, Accepted: May 24, 2021, ePublished: October 1, 2021

\section{Introduction}

Severe acute respiratory syndrome coronavirus 2 (SARS$\mathrm{CoV}-2)$ is a newly recognized disease that has spread rapidly from Wuhan (Hubei province) to other provinces in China and around the world. ${ }^{1,2}$ Since the outbreak of the new coronavirus pneumonia, with the rapid spread in the country and even the world, the number of infected cases has increased exponentially.,4

The rapid spread of COVID-19 has attracted worldwide attention, and the World Health Organization (WHO) has designated it as a public health emergency, international concern, and pandemic. ${ }^{5,6}$ The spread of COVID-19 has

*Corresponding Author: Seyed-Saeed Hashemi-Nazari, MD, PhD; Prevention of Cardiovascular Disease Research Center, Department of Epidemiology, School of Public Health and Safety, Shahid Beheshti University of Medical Sciences, Tehran, Iran. Tel: +98-21-22431993; Fax: +98-21-22439784; Email: saeedh_1999@ yahoo.com

\#Contributed equally to the work as first authors. 
been shown to occur in individuals through droplets, aerosols, feces, and oral mucosa. ${ }^{7}$ Clinical manifestations of the patients include fever, dry cough, shortness of breath, myalgia, olfactory and taste dysfunction, fatigue, normal or decreased leukocyte count, and radiographic evidence of pneumonia. Organ dysfunction (such as shock, acute respiratory distress syndrome [ARDS], acute heart injury, liver and acute kidney injury) and death may occur in severe cases. ${ }^{8-13}$

Age and gender are known as risk factors for the severe consequences of COVID-19 in which more than $90 \%$ of COVID-19-related deaths in the UK have occurred in people over 60 years and $60 \%$ in men. ${ }^{14}$

Various pre-existing conditions have also been associated with increased risk. For example, the China Center for Disease Control and Prevention in a study of 44,672 people (1023 deaths) reported that cardiovascular disease, hypertension, diabetes, respiratory disease, and cancer were associated with an increased risk of death. ${ }^{15}$ Also, one of the largest reports of 44000 people with COVID-19 showed that older age, cardiovascular disease, diabetes, chronic respiratory disease, high blood pressure and cancer were linked with mortality following COVID-19. ${ }^{16}$ A meta-analysis of eight studies consisting of 46,248 patients with a positive COVID-19 test showed that most people with severe disease were more likely to have high blood pressure (odds ratio: 2.36), respiratory disease (odds ratio: 2.46) and cardiovascular disease (odds ratio: 3.42$).{ }^{17}$

Given the recent COVID-19 pandemic and the rising number of morbidities and deaths worldwide, the collection and review of various studies on the disease could pave the way for further steps to better understand its nature and pathogenesis and help in the prevention, diagnosis and appropriate treatment of this disease. The aim of this study was to describe the epidemiological features, symptoms and mortality of the patients with COVID-19 in six provinces in different regions of Iran.

\section{Materials and Methods}

This was a cohort study performed on 103,179 hospitalized patients with COVID-19. The demographic and clinical data of the patients with COVID-19, hospitalized patients with confirmed (PCR-positive), probable (CT-positive), and suspected (diagnosed by a physician based on symptoms) diagnosis in Tehran, Kermanshah, Hamedan, Kurdistan, Sistan and Baluchestan, and Chaharmahal and Bakhtiari provinces were collected. Provinces were selected from different areas of the country based on special climatic and cultural conditions and access to data.

All hospitalized patients were registered in the electronic syndromic surveillance system for the early detection of infectious disease epidemics in Iran. This registration system includes questions about demographics (8 questions), clinical conditions (27 questions), history of exposure (19 questions), symptoms (22 questions), underlying diseases (9 questions), and pregnancy (3 questions). The available data spans the period from February 20, 2020 to November 5, 2020. The list of all patients was extracted from the electronic syndromic surveillance system for COVID-19 and all data of the patients with COVID-19 with different time intervals (time from onset of symptoms to hospitalization, onset of symptoms to isolation, onset of symptoms to death, onset of symptoms to discharge, hospitalization to death). In addition to these, clinical symptoms were monitored by researchers. This registration system does not have underreporting. However, some variables had missing data. In the course of analysis, impossible range data and outliers were taken into consideration. Finally, after extracting the data, it was cleaned and analyzed. Continuous data were reported as mean and standard deviation (SD) and qualitative data were reported as frequency and percentage. STATA version 14 and Excel 2016 were used for data analysis.

\section{Results}

The present study was performed on 103179 patients (men: 56942 and women: 46237) with COVID-19. The mean age of the patients was $52.41 \pm 20.79$ years. It was $52.41 \pm 20.90$ years for women and $52.40 \pm 20.72$ for men. We had 8,348 (8.09\%) deaths throughout the study. Also, at the time of the study, 74,542 (72.25\%) patients had recovered and 20289 (19.66\%) were under treatment. There were 5085 (60.9\%) deaths among men and $3263(39.1 \%)$ among women, indicating that the death rate among men was higher than women. Clinical time-interval parameters in COVID -19 were evaluated according to age and gender. The results showed that the mean time from onset of symptoms to hospitalization in men and women were $3.47 \pm 2.11$ and $3.48 \pm 2.07$ days, respectively. The mean time from onset of symptoms to isolation was $2.81 \pm 3.19$ days in men and $2.87 \pm 3.38$ days in women. In men and women, the mean time from onset of symptoms to death was $9.29 \pm 7.26$ and $9.54 \pm 7.95$ days, respectively. The mean time from onset of symptoms to discharge was $7.47 \pm 6.31$ days in men and $7.39 \pm 6.32$ days in women. Finally, the mean time from hospitalization to death was $6.76 \pm 6.91$ days for men and $7.05 \pm 7.28$ days for women (Table 1 ).

Table 1 shows the average time intervals by standardized age. These standardized averages were lower according to the findings in most of the items. But this average was higher in both sexes in the item of hospitalization to death.

Figure 1 shows the relative frequency of different age groups in the hospitalized patients for men and women and Figure 2 presents the relative frequency of different age groups in the deceased patients for men and women. These values are higher for both sexes hospitalized in the middle age groups while death occurred more frequently in older age groups.

The relative frequency of the incidence of symptoms was evaluated in the patients. The results showed that cough was the most common symptom in the patients 
Table 1. Estimation of Clinical Time Intervals Parameters in COVID-19 Disease Across Age and Gender Groups

\begin{tabular}{|c|c|c|c|c|c|c|c|c|c|c|}
\hline \multirow[t]{2}{*}{ Age Group } & \multicolumn{2}{|c|}{$\begin{array}{l}\text { Time From Hospitalization } \\
\text { to Death }\end{array}$} & \multicolumn{2}{|c|}{$\begin{array}{l}\text { Time From Onset of } \\
\text { Symptoms to Discharge }\end{array}$} & \multicolumn{2}{|c|}{$\begin{array}{l}\text { Time From Onset of } \\
\text { Symptoms to Death }\end{array}$} & \multicolumn{2}{|c|}{$\begin{array}{l}\text { Time From Onset of } \\
\text { Symptoms to Isolation }\end{array}$} & \multicolumn{2}{|c|}{$\begin{array}{l}\text { Time From Onset } \\
\text { of Symptoms to } \\
\text { Hospitalization }\end{array}$} \\
\hline & Male & Female & Male & Female & Male & Female & Male & Female & Male & Female \\
\hline$<5$ & $5.62 \pm 6.47$ & $7.76 \pm 8.65$ & $7.58 \pm 5.72$ & $8.40 \pm 7.37$ & $7.07 \pm 6.92$ & $9.76 \pm 9.75$ & $2.43 \pm 2.87$ & $2.79 \pm 4.02$ & $3.29 \pm 1.77$ & $3.28 \pm 1.75$ \\
\hline $5-10$ & $6.27 \pm 7.91$ & $7.36 \pm 8.18$ & $8.38 \pm 7.55$ & $7.62 \pm 5.83$ & $8.93 \pm 12.28$ & $8.64 \pm 9.63$ & $2.44 \pm 3.31$ & $2.42 \pm 3.43$ & $3.32 \pm 2.05$ & $3.23 \pm 1.97$ \\
\hline $10-15$ & $6.15 \pm 4.86$ & $11.33 \pm 11.05$ & $6.88 \pm 5.68$ & $7.17 \pm 5.85$ & $7.38 \pm 4.90$ & $12.20 \pm 9.58$ & $1.99 \pm 2.37$ & $1.62 \pm 2.00$ & $3.26 \pm 1.76$ & $3.19 \pm 1.52$ \\
\hline $15-20$ & $6.43 \pm 7.12$ & $7.44 \pm 8.46$ & $5.72 \pm 5.49$ & $6.65 \pm 5.91$ & $6.66 \pm 4.70$ & $8.00 \pm 5.77$ & $2.20 \pm 2.34$ & $2.15 \pm 2.22$ & $3.26 \pm 1.85$ & $3.30 \pm 1.53$ \\
\hline $20-25$ & $6.25 \pm 4.75$ & $8.78 \pm 7.23$ & $5.52 \pm 6.02$ & $5.99 \pm 5.50$ & $8.66 \pm 6.74$ & $11.26 \pm 8.90$ & $2.65 \pm 3.44$ & $2.66 \pm 2.78$ & $3.44 \pm 1.82$ & $3.42 \pm 1.87$ \\
\hline $25-30$ & $9.55 \pm 7.18$ & $10.10 \pm 9.29$ & $6.24 \pm 6.12$ & $6.11 \pm 5.94$ & $9.97 \pm 9.01$ & $11.43 \pm 8.47$ & $2.59 \pm 3.05$ & $2.62 \pm 3.33$ & $3.46 \pm 1.93$ & $3.45 \pm 1.84$ \\
\hline $30-35$ & $6.38 \pm 7.41$ & $7.33 \pm 5.21$ & $6.36 \pm 6.04$ & $6.16 \pm 5.97$ & $9.26 \pm 7.45$ & $9.71 \pm 9.84$ & $2.57 \pm 2.99$ & $2.59 \pm 2.88$ & $3.45 \pm 1.99$ & $3.55 \pm 1.98$ \\
\hline $35-40$ & $6.98 \pm 7.13$ & $5.11 \pm 8.54$ & $6.95 \pm 6.25$ & $6.43 \pm 5.92$ & $9.21 \pm 8.30$ & $8.47 \pm 7.52$ & $3.04 \pm 3.32$ & $2.87 \pm 3.30$ & $3.56 \pm 2.12$ & $3.55 \pm 2.04$ \\
\hline $40-45$ & $7.83 \pm 8.26$ & $7.40 \pm 5.23$ & $7.01 \pm 5.89$ & $6.70 \pm 6.13$ & $10.73 \pm 8.65$ & $9.22 \pm 6.93$ & $2.97 \pm 3.35$ & $3.36 \pm 3.82$ & $3.58 \pm 2.17$ & $3.59 \pm 2.13$ \\
\hline $45-50$ & $6.14 \pm 5.69$ & $6.05 \pm 7.65$ & $7.55 \pm 6.37$ & $7.36 \pm 6.33$ & $8.97 \pm 6.76$ & $8.51 \pm 7.75$ & $3.13 \pm 3.44$ & $3.37 \pm 3.90$ & $3.60 \pm 2.22$ & $3.61 \pm 2.32$ \\
\hline $50-55$ & $6.16 \pm 6.04$ & $6.34 \pm 6.20$ & $7.85 \pm 6.47$ & $7.61 \pm 6.38$ & $8.77 \pm 6.74$ & $9.26 \pm 7.21$ & $3.02 \pm 3.33$ & $3.03 \pm 3.37$ & $3.54 \pm 2.25$ & $3.57 \pm 2.24$ \\
\hline $55-60$ & $7.50 \pm 7.03$ & $7.25 \pm 6.47$ & $8.12 \pm 6.61$ & $8.16 \pm 6.31$ & $10.36 \pm 8.08$ & $9.89 \pm 7.77$ & $2.82 \pm 3.16$ & $2.80 \pm 3.14$ & $3.53 \pm 2.28$ & $3.56 \pm 2.10$ \\
\hline $60-65$ & $6.56 \pm 6.14$ & $7.78 \pm 7.07$ & $8.34 \pm 6.38$ & $8.54 \pm 6.76$ & $9.18 \pm 7.00$ & $10.20 \pm 9.26$ & $2.88 \pm 3.20$ & $3.13 \pm 3.91$ & $3.50 \pm 2.13$ & $3.39 \pm 2.05$ \\
\hline $65-70$ & $6.35 \pm 6.23$ & $7.20 \pm 7.21$ & $8.19 \pm 6.37$ & $8.52 \pm 6.68$ & $8.97 \pm 6.74$ & $10.01 \pm 8.04$ & $2.99 \pm 3.32$ & $2.94 \pm 3.28$ & $3.50 \pm 2.21$ & $3.51 \pm 2.28$ \\
\hline $70-75$ & $6.89 \pm 6.39$ & $6.51 \pm 6.07$ & $8.25 \pm 6.44$ & $8.37 \pm 6.47$ & $9.43 \pm 7.44$ & $9.32 \pm 8.12$ & $2.79 \pm 3.25$ & $2.98 \pm 3.42$ & $3.34 \pm 2.13$ & $3.38 \pm 2.11$ \\
\hline $75-80$ & $6.55 \pm 7.07$ & $7.39 \pm 7.12$ & $8.19 \pm 6.36$ & $8.5 \pm 6.55$ & $9.25 \pm 7.34$ & $9.73 \pm 7.85$ & $2.65 \pm 3.88$ & $2.87 \pm 3.40$ & $3.42 \pm 2.07$ & $3.38 \pm 2.04$ \\
\hline 80-85 & $7.22 \pm 6.40$ & $6.76 \pm 6.27$ & $8.14 \pm 6.12$ & $7.87 \pm 6.75$ & $9.54 \pm 7.29$ & $9.14 \pm 6.97$ & $2.73 \pm 3.07$ & $2.47 \pm 2.98$ & $3.31 \pm 2.01$ & $3.36 \pm 2.02$ \\
\hline $85>$ & $6.59 \pm 6.23$ & $6.84 \pm 6.70$ & $8.25 \pm 6.24$ & $7.72 \pm 6.22$ & $9.02 \pm 7.19$ & $9.25 \pm 7.86$ & $2.53 \pm 3.01$ & $2.48 \pm 2.94$ & $3.25 \pm 2.00$ & $3.35 \pm 1.92$ \\
\hline Total & $6.76 \pm 6.91$ & $7.05 \pm 7.28$ & $7.47 \pm 6.31$ & $7.39 \pm 6.32$ & $9.29 \pm 7.26$ & $9.54 \pm 7.95$ & $2.81 \pm 3.19$ & $2.87 \pm 3.38$ & $3.47 \pm 2.11$ & $3.48 \pm 2.07$ \\
\hline $\begin{array}{l}\text { Age } \\
\text { standardized }\end{array}$ & $6.80 \pm 5.02$ & $7.72 \pm 6.41$ & $7.04 \pm 5.63$ & $7.06 \pm 5.74$ & $8.85 \pm 6.08$ & $9.77 \pm 6.50$ & $2.65 \pm 1.97$ & $2.70 \pm 2.34$ & $3.43 \pm 1.82$ & $3.44 \pm 1.19$ \\
\hline
\end{tabular}

in all provinces. The relative frequency of the three symptoms of fever and chills, cough and shortness of breath was lower in the patients from the Tehran province than other provinces. Table 2 shows the relative frequency of the prevalence of symptoms in the studied provinces across genders.

Regarding the outcome of COVID-19 in male and female patients, the use of ventilator, ICU admission, pregnancy, comorbidity, occupation and travel and contact history of the patients were studied (Table 3). The results showed that the frequency of ICU admission was higher in men under treatment than women $(40.77 \%$ vs. 11.16 $\%)$. The most common comorbidity was cardiovascular disease in women who died $(27.70 \%)$, those who were still under treatment (13.57\%) and those who recovered (13.27\%). Cardiovascular disease was also the most common comorbidity in men who died $(22.39 \%)$, those who were still under treatment $(12.31 \%)$ and those who recovered (11.73\%). Diabetes had the second rank among comorbidities.

Among the occupations of patients were 10692 medical staff (male 4761 [44.5\%] female 5931 [55.5\%]) student

1054 (male 698 [66.2\%] female 356 [33.8\%]) laboratory staff 299 (male 143 [47.8\%] female 156 [52.2\%]) and in contact with the animal 130 (male 110 [84.6\%] female 20 [15.4\%]).

For discharged or recovered patients, the highest frequency of occupations were contact with animal and student $(91.8 \%$ and $86.6 \%$ for men; $100.0 \%$ and $82.6 \%$ for women, respectively), whereas for patients under treatment, the occupations of laboratory and medical staff (24.5\% and $23.4 \%$ for men; $26.9 \%$ and $23.9 \%$ for women, respectively) were more frequently than others. In cases of death, the highest mortality percentage was observed in contact with animals men (5.4\%) and female students (4.2\%).

Around $60.9 \%$ of deaths occurred in men. The mean age of death was $67.37 \pm 18.63$ years in women and $66.17 \pm 18.04$ years in men. Figure 3 shows in-hospital mortality across age groups and genders.

\section{Discussion}

The present study was done to describe the epidemiological features, symptoms and mortality of the patients with COVID-19 in some provinces of Iran (Tehran, Kermanshah, Hamedan, Kurdistan, Sistan and Baluchestan, and Chaharmahal and Bakhtiari). Considering the fact that the sample size of this study is large enough $(n=103,179)$, it can be used as a suitable research for diagnostic targets and decision-making by policymakers. In summary, we found that the mean time from onset of symptoms to hospitalization, the mean time from onset of symptoms to isolation, the mean time from onset of symptoms to death, the mean time from 


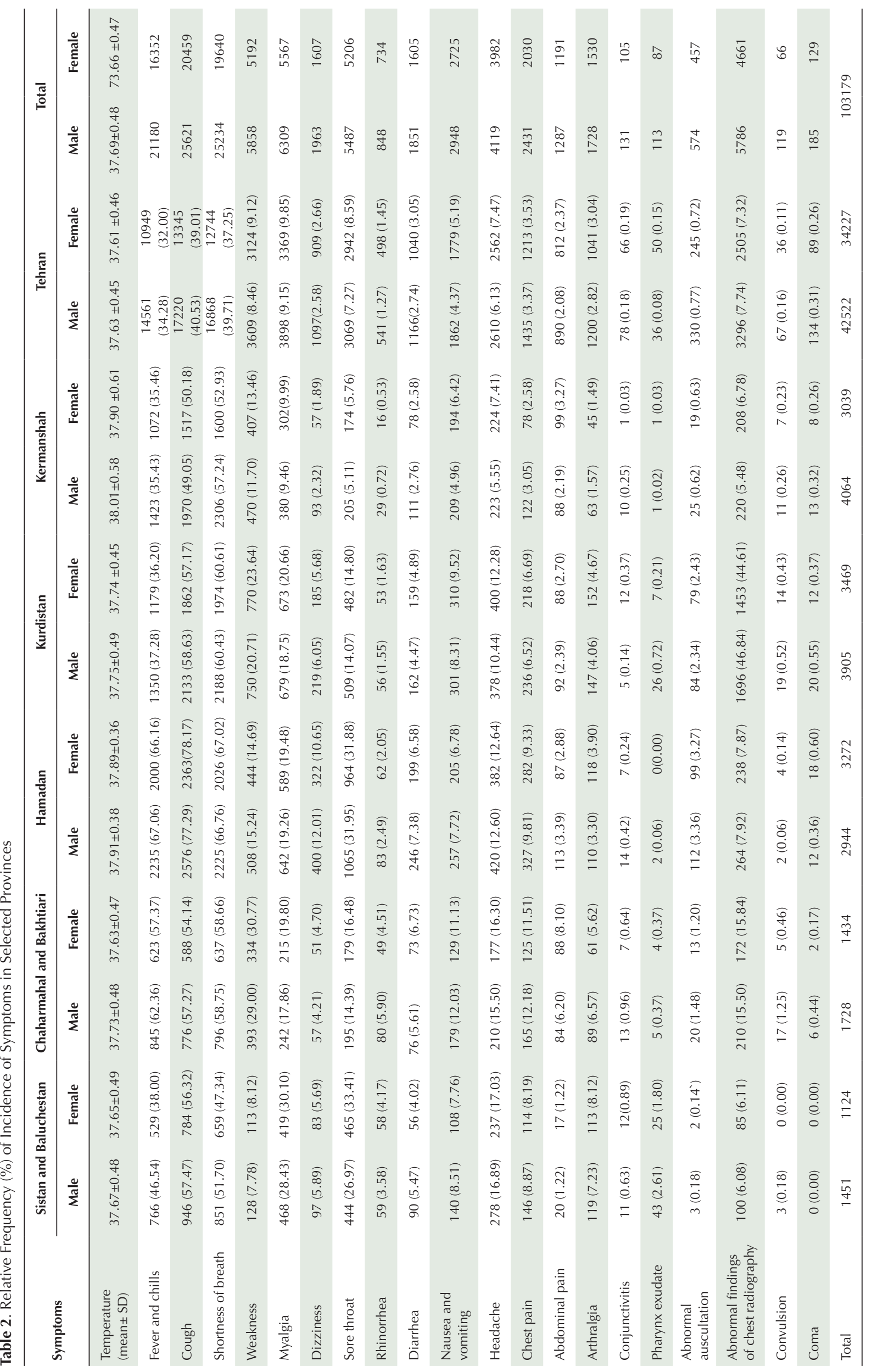




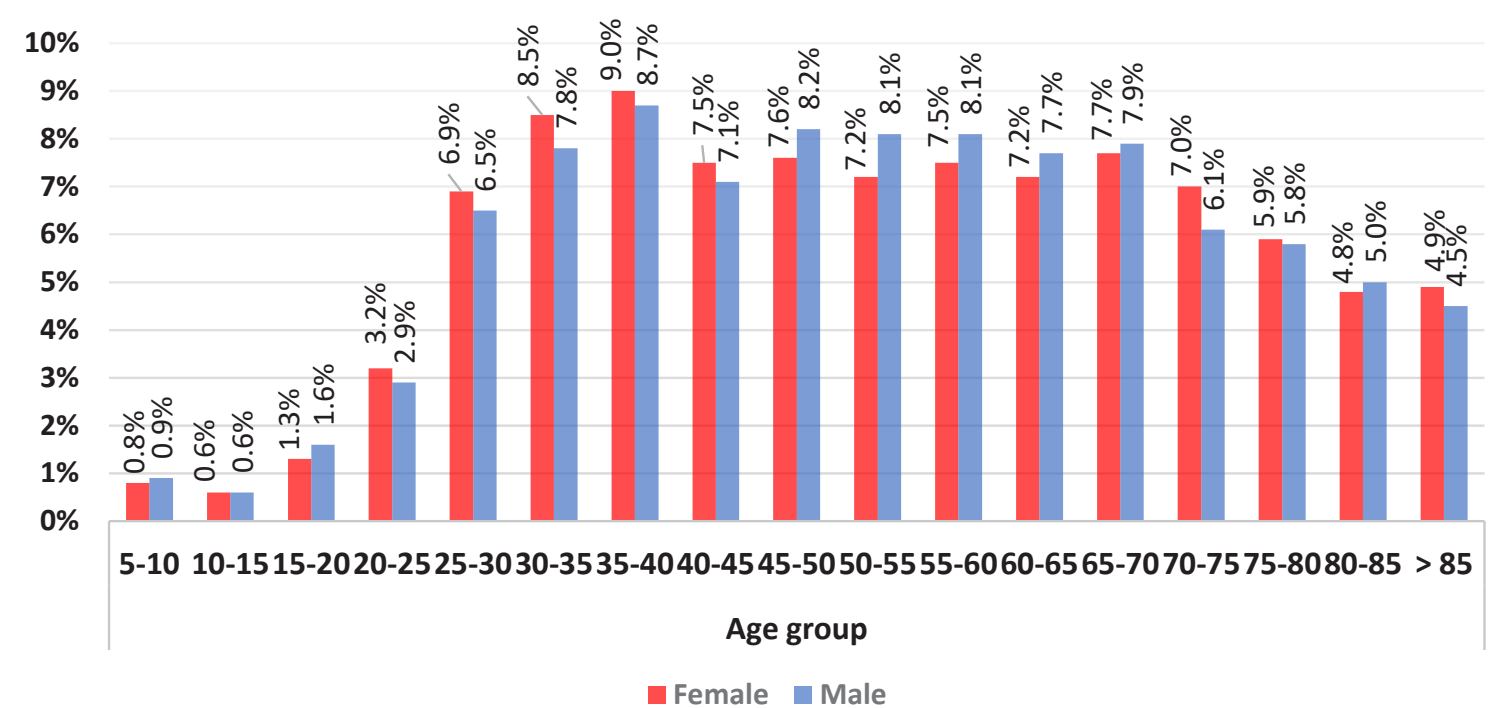

Figure 1. Relative Frequency of Hospitalization by Gender in Different Age Groups.

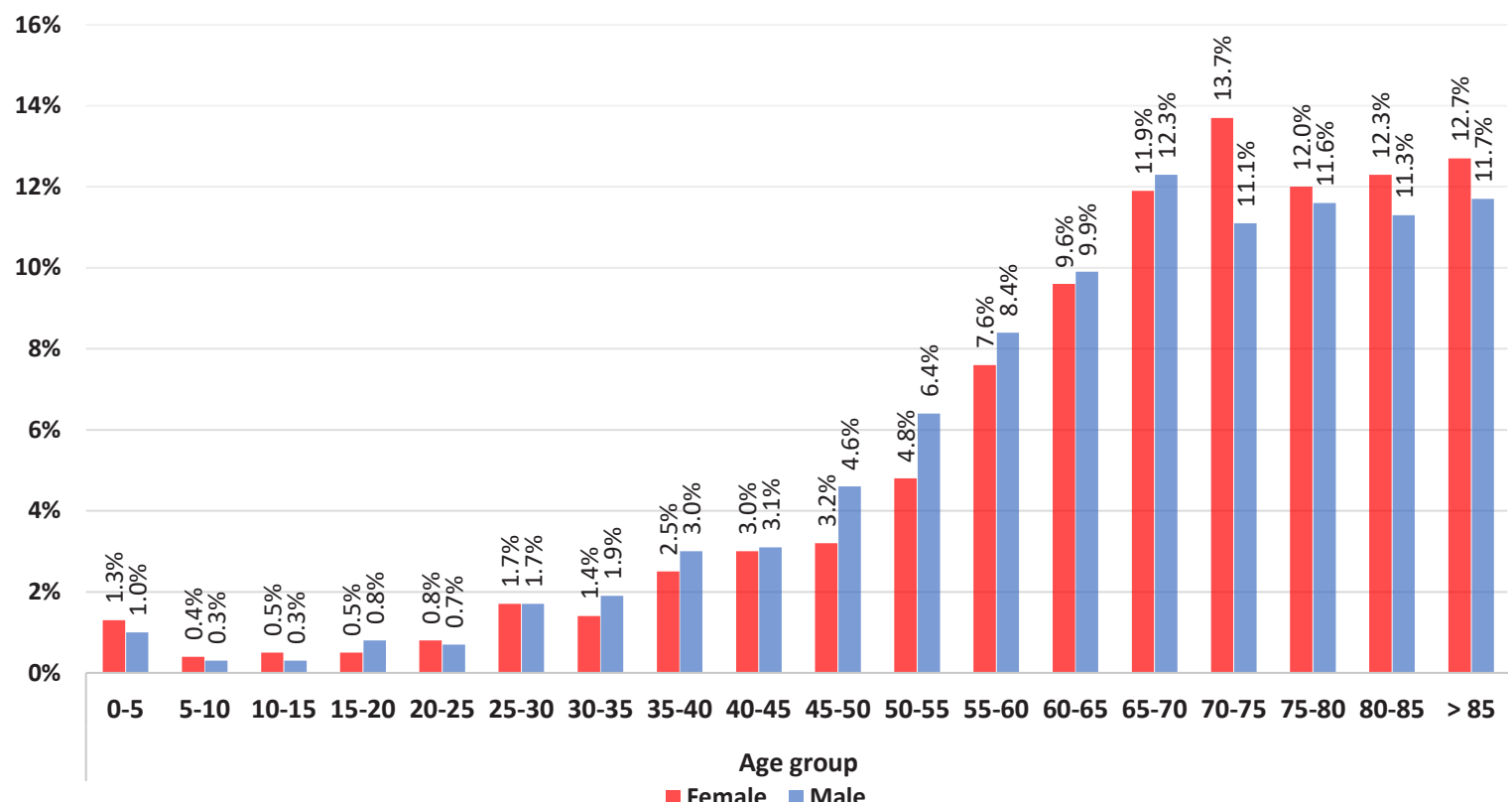

Figure 2. Relative Frequency of Mortality by Gender in Different Age Groups.

onset of symptoms to discharge, and the mean time from hospitalization to death were similar in men and women. Cough, shortness of breath and fever were the most common symptoms in the studied patients. Furthermore, at the time of the study, $72.25 \%$ of the patients had recovery and $8.09 \%$ of the patients died.

In China, the median age of patients was 47.5 years and about $50 \%$ were men. Of the affected patients, $60.4 \%$ had close contact with confirmed cases, and $10.9 \%$ had no close contact history. The most common symptom at the onset of illness was fever (82.1\%). Next, cough was observed in $45.8 \%$ of the patients, and the mortality of COVID-19 was $0.9 \%{ }^{18}$ In the United States, the median age was 62.2 years and $60.6 \%$ were men. The most common symptom was reported to be cough in about $80 \%$ and fever in $78 \%$. In total, $10.2 \%$ of the patients died, and $66.2 \%$ were discharged from the hospitals. ${ }^{19}$ Mortality rate in Italy was different, as the mortality rate of COVID-19 was $0.7 \%$ for the age group of 4-49 years, $7.27 \%$ for people over 80 years, and $9.96 \%$ for people over 60 years. ${ }^{20}$ In South Korea, with more efforts to identify patients and a strong health care capacity, the current mortality rate for people over 80 was reported to be $18.31 \%{ }^{21}$ The pattern of age, sex and death in our study was lower than the study by Goyal et al, ${ }^{19}$ but the mean age of our patients was higher than the findings reported by Tian et al. ${ }^{18}$ However, the distribution of age and gender groups in each community affects these results. The prevalence of clinical symptoms was also similar with findings of the article related to the US population compared to China. ${ }^{18,19}$

The frequency of ICU admission was higher in men than women. The most common comorbidity was 
Table 3. Clinical and Demographic Characteristics of the Patients According to the Outcome by Gender

\begin{tabular}{|c|c|c|c|c|c|c|}
\hline \multirow{2}{*}{ Variable } & \multicolumn{2}{|c|}{ Recovery } & \multicolumn{2}{|c|}{ Under treatment } & \multicolumn{2}{|c|}{ Deaths } \\
\hline & Male, n (\%) & Female, n (\%) & Male, n (\%) & Female, n (\%) & Male, n (\%) & Female, n (\%) \\
\hline Use of ventilator & 1987 (10.92) & \multirow{2}{*}{$\begin{array}{l}1562(10.04) \\
2522(12.23)\end{array}$} & $889(16.44)$ & 739 (16.67) & $764(30.40)$ & $523(30.50)$ \\
\hline Admitted in ICU & $3328(13.14)$ & & $1247(40.75)$ & $585(11.16)$ & $1247(40.75)$ & $847(40.72)$ \\
\hline Pregnant & - & $607(1.82)$ & - & $141(1.49)$ & - & $13(0.49)$ \\
\hline \multicolumn{7}{|l|}{ Comorbidity } \\
\hline Immunodeficiency & $120(0.29)$ & $128(0.38)$ & $28(0.26)$ & $29(0.31)$ & $24(0.48)$ & $128(0.71)$ \\
\hline Cardiovascular disease & $4787(11.73)$ & $4422(13.27)$ & $1317(12.31)$ & $1286(13.57)$ & $1130(22.39)$ & $897(27.70)$ \\
\hline Diabetes & $2361(5.79)$ & $2531(7.60)$ & $646(6.04)$ & $736(7.77)$ & $560(11.10)$ & $488(15.07)$ \\
\hline Liver disease & $182(0.45)$ & $123(0.37)$ & $49(0.46)$ & $53(0.56)$ & $50(1.00)$ & $28(0.86)$ \\
\hline Renal disease & $969(2.37)$ & $670(2.01)$ & $255(2.38)$ & $154(1.63)$ & $216(4.28)$ & $147(4.54)$ \\
\hline Chronic neurological disease & $285(0.70)$ & $298(0.89)$ & $72(0.67)$ & $65(0.69)$ & $73(1.45)$ & $62(1.91)$ \\
\hline Chronic pulmonary disease & $1215(2.98)$ & $963(2.89)$ & $260(2.43)$ & $212(2.24)$ & $276(5.47)$ & $189(5.84)$ \\
\hline \multicolumn{7}{|l|}{ Occupation } \\
\hline Student & $605(1.48)$ & $294(0.89)$ & $81(0.77)$ & $47(0.50)$ & $12(0.24)$ & $15(0.46)$ \\
\hline Medical staff & $3625(8.88)$ & $4503(13.52)$ & $1114(10.41)$ & $1421(15.01)$ & $22(0.44)$ & $7(0.22)$ \\
\hline Laboratory staff & $107(0.26)$ & $114(0.34)$ & $35(0.32)$ & $42(0.44)$ & $1(0.02)$ & $0(0.00)$ \\
\hline In contact with the animal & $101(0.25)$ & $20(0.06)$ & $3(0.03)$ & $0(0.00)$ & $6(0.12)$ & $0(0.00)$ \\
\hline \multicolumn{7}{|l|}{ Contact and travel history } \\
\hline Travel history in the last 14 days & $375(0.93)$ & $256(0.76)$ & $128(1.20)$ & $72(0.76)$ & $31(0.61)$ & $18(0.56)$ \\
\hline $\begin{array}{l}\text { Present the health center in the last } 14 \\
\text { days }\end{array}$ & $987(2.42)$ & $927(2.78)$ & $156(1.46)$ & $171(1.81)$ & $128(2.54)$ & $78(2.41)$ \\
\hline $\begin{array}{l}\text { History of contact with a respiratory } \\
\text { disease patient in the last } 14 \text { days }\end{array}$ & $2172(5.32)$ & $2361(7.09)$ & $361(3.37)$ & $358(3.78)$ & $80(1.59)$ & $61(1.88)$ \\
\hline $\begin{array}{l}\text { History of contact with a respiratory } \\
\text { patient in medical centers }\end{array}$ & $867(2.12)$ & $1189(3.57)$ & 159 (1.49) & $171(1.81)$ & $20(0.40)$ & $17(0.53)$ \\
\hline $\begin{array}{l}\text { History of contact with a respiratory } \\
\text { patient in family }\end{array}$ & $557(1.36)$ & 565 (1.97) & $119(1.11)$ & $147(1.55)$ & $48(0.95)$ & 37 (1.14) \\
\hline $\begin{array}{l}\text { History of contact with a respiratory } \\
\text { patient in workplace }\end{array}$ & 1203 (2.95) & $1386(4.16)$ & 177 (1.65) & $174(1.84)$ & $9(0.18)$ & $2(0.06)$ \\
\hline $\begin{array}{l}\text { History of contact with a confirmed } \\
\text { patient }\end{array}$ & $1550(3.80)$ & $1780(5.34)$ & $244(2.28)$ & $254(2.67)$ & $51(1.01)$ & $49(1.50)$ \\
\hline
\end{tabular}

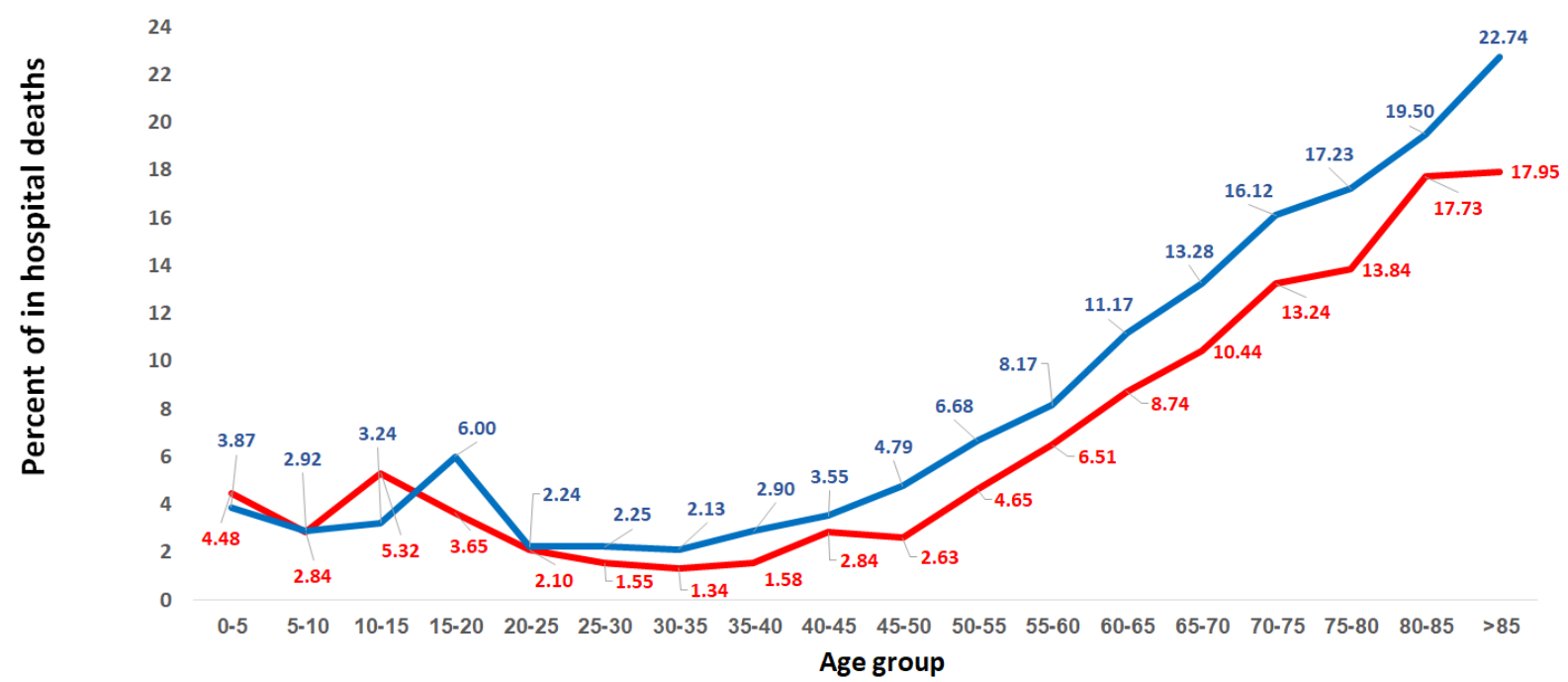

Figure 3. Percentage of In-hospital Mortality Across Age Groups and Genders. 
cardiovascular disease in women and men. The mean age of death was similar in women and men. According to a study conducted by Chen et al in China in 2020 on 99 patients who were diagnosed with COVID-19 using laboratory tests, the virus was more prevalent in older men with underlying diseases. People with high blood pressure, cardiovascular disease and history of smoking were more likely to get COVID-19 and these people were more likely to die from the COVID-19. ${ }^{2}$ Wang et al reported that 138 patients with COVID-19 who were admitted to hospital had a mean age of 56 years, and 75 patients were male. It was also reported that patients admitted to the ICU were older than those admitted to conventional hospital wards and had more comorbidities. ${ }^{22}$ These results are consistent with our findings because we found that male gender and advanced age as risk factor for COVID-19. In addition, a meta-analysis by Zhang et al examining 13 articles on the risk factors for mortality following COVID-19 found that male gender, age over 65 years, and smoking conferred a higher risk for the severe form of COVID-19.23 Also, in another review by Rod et al. which reviewed 17 articles on the risk factors for morbidity and mortality in patients with COVID-19, it was reported that aging, high D-dimer, C reactive protein, higher Sequential Organ Failure Assessment (SOFA) score and history of diabetes were among the most important and main risk factors that affected the mortality of COVID-19. ${ }^{24}$ We found that cardiovascular disease was the most common comorbidity among the patients. Similar to our results, other studies showed the same. ${ }^{1,23}$ In a study by Yang et al, it was reported that comorbidities such as hypertension, cardiovascular and respiratory diseases were risk factors for the severe forms of COVID-19. ${ }^{17}$ Zhou et al in China surveyed 191 patients with COVID-19 who were hospitalized and were over 18 years of age. They reported that most of the patients had hypertension, diabetes, and coronary artery disease, and it was also reported that the mortality rate of patients increased with age..$^{25}$

Pan et al reported that in patients recovering from COVID-19 pneumonia, lung abnormalities on chest CT are maximum 10 days after the first symptoms. ${ }^{26}$ It shows that in some patients, it is possible that the conditions become worse after 10 days. Chen et al indicated that many patients had been discharged after 16 days. ${ }^{27}$ In a study by Besharat et al, the results showed that $71 \%$ of patients were male and the mean age was 67.62 years with symptoms lasting 6.24 days. $^{28}$ This study was consistent with our results regarding the duration of the symptoms that may be related to the genetics (level of ACE2 receptors) of the same population. ${ }^{29}$ Like our study, Besharat et al reported that fever, cough, and shortness of breath were dominant symptoms. $^{28}$

In conclusion, according to the results, the mean time from onset of symptoms to hospitalization, isolation, and discharge were similar in women and men. ICU admission was about four times higher in men than women and the most common comorbidity in women and men was cardiovascular disease and diabetes. Regarding mortality, the overall mortality rate was higher in men than women, but in the strata of cardiovascular and diabetes disease, the percentage of death in women was higher than men.

\section{Authors' Contribution}

SSHN and AZ: Study design and preparing condition. FN, MK, GM, $A M H, A A h, M S, M S h, E N, M J$ and $A B$ : Data gathering. FKS and AAm: Screening and data analysis. AAm, FKS and SSHN: Article writing.

\section{Conflict of Interest Disclosures}

None.

\section{Ethical Statement}

All colleagues attention followed the principles of ethics in carrying out project, collection collecting and recording data, as well as in maintaining patients' personal information.

\section{References}

1. Huang C, Wang Y, Li X, Ren L, Zhao J, Hu Y, et al. Clinical features of patients infected with 2019 novel coronavirus in Wuhan, China. Lancet. 2020;395(10223):497-506. doi: 10.1016/s0140-6736(20)30183-5.

2. Chen N, Zhou M, Dong X, Qu J, Gong F, Han Y, et al. Epidemiological and clinical characteristics of 99 cases of 2019 novel coronavirus pneumonia in Wuhan, China: a descriptive study. Lancet. 2020;395(10223):507-13. doi: 10.1016/s0140-6736(20)30211-7.

3. Guan WJ, Ni ZY, Hu Y, Liang WH, Ou CQ, He JX, et al. Clinical characteristics of coronavirus disease 2019 in China. N Engl J Med. 2020;382(18):1708-20. doi: 10.1056/NEJMoa2002032.

4. Daneshfar M, Dadashzadeh N, Ahmadpour M, Ragati Haghi H, Rahmani V, Frouzesh M, et al. Lessons of mortality following COVID-19 epidemic in the United States especially in the geriatrics. J Nephropharmacol. 2021;10(1):e06. doi: 10.34172/npj.2021.06.

5. Yang X, Yu Y, Xu J, Shu H, Xia J, Liu H, et al. Clinical course and outcomes of critically ill patients with SARS-CoV-2 pneumonia in Wuhan, China: a single-centered, retrospective, observational study. Lancet Respir Med. 2020;8(5):475-81. doi: 10.1016/s2213-2600(20)30079-5.

6. World Health Organization. Coronavirus disease 2019 (COVID-19) Situation Report-51. Available from: https:// www.who.intsimplehttps://www.who.int. Accessed April 2021.

7. Wang C, Horby PW, Hayden FG, Gao GF. A novel coronavirus outbreak of global health concern. Lancet. 2020;395(10223):470-3. doi: 10.1016/s0140-6736(20)301859.

8. Samimi Ardestani SH, Mohammadi Ardehali M, Rabbani Anari M, Rahmaty B, Erfanian R, Akbari M, et al. The coronavirus disease 2019: the prevalence, prognosis, and recovery from olfactory dysfunction (OD). Acta Otolaryngol. 2021;141(2):171-80. doi: 10.1080/00016489.2020.1836397.

9. Rahimzadeh P, Faiz HR, Farahmandrad R, Hassanlouei B, Habibi A, Hedayati Emami S, et al. Clinical features and prognosis of invasive ventilation in hospitalized patients with COVID-19: a retrospective study. Anesth Pain Med. 2020;10(6):e108773. doi: 10.5812/aapm.108773.

10. National Health Service England. COVID-19 daily deaths. Available from: https://www.england.nhs.uk/statistics/ statistical-work-areas/covid-19-daily-deaths. Accessed March 2021.

11. Forest SJ, Michler RE, Skendelas JP, DeRose JJ, Friedmann P, Parides MK, et al. De novo renal failure and clinical outcomes of patients with critical coronavirus disease 2019. Crit Care Med. 
2021;49(2):e161-e9. doi: 10.1097/ccm.0000000000004785.

12. Grasselli G, Tonetti T, Filippini C, Slutsky AS, Pesenti A, Ranieri VM. Pathophysiology of COVID-19-associated acute respiratory distress syndrome - Authors' reply. Lancet Respir Med. 2021;9(1):e5-e6. doi: 10.1016/s2213-2600(20)30525-7.

13. Valizadeh R, Dadashzadeh N, Zakeri R, James Kellner S, Mohammad Rahimi M. Drug therapy in hospitalized patients with very severe symptoms following COVID-19. J Nephropharmacol. 2020;9(2):e21. doi: 10.34172/ npj.2020.21.

14. Mohammad Rahimi M, Jahantabi E, Lotfi B, Forouzesh M, Valizadeh R, Farshid S. Renal and liver injury following the treatment of COVID-19 by remdesivir. J Nephropathol. 2021;10(2):e10. doi: 10.34172/jnp.2021.10.

15. Deng G, Yin $M$, Chen X, Zeng F. Clinical determinants for fatality of 44,672 patients with COVID-19. Crit Care. 2020;24(1):179. doi: 10.1186/s13054-020-02902-w.

16. Wu Z, McGoogan JM. Characteristics of and important lessons from the coronavirus disease 2019 (COVID-19) outbreak in China: summary of a report of 72314 cases from the Chinese Center for Disease Control and Prevention. JAMA. 2020;323(13):1239-42. doi: 10.1001/jama.2020.2648.

17. Yang J, Zheng Y, Gou X, Pu K, Chen Z, Guo Q, et al. Prevalence of comorbidities and its effects in patients infected with SARSCoV-2: a systematic review and meta-analysis. Int J Infect Dis. 2020;94:91-5. doi: 10.1016/j.ijid.2020.03.017.

18. Tian S, Hu N, Lou J, Chen K, Kang X, Xiang Z, et al. Characteristics of COVID-19 infection in Beijing. J Infect. 2020;80(4):401-6. doi: 10.1016/j.jinf.2020.02.018.

19. Goyal P, Choi JJ, Pinheiro LC, Schenck EJ, Chen R, Jabri A, et al. Clinical Characteristics of COVID-19 in New York City. N Engl J Med. 2020;382(24):2372-4. doi: 10.1056/NEJMc2010419.

20. Yanez ND, Weiss NS, Romand JA, Treggiari MM. COVID-19 mortality risk for older men and women. BMC Public Health. 2020;20(1):1742. doi: 10.1186/s12889-020-09826-8.

21. Sonn JW, Lee JK. The smart city as time-space cartographer in
COVID-19 control: the South Korean strategy and democratic control of surveillance technology. Eurasian Geogr Econ. 2020;61(4-5):482-92. doi:10.1080/15387216.2020.1768423.

22. Wang D, Hu B, Hu C, Zhu F, Liu X, Zhang J, et al. Clinical characteristics of 138 hospitalized patients with 2019 novel coronavirus-infected pneumonia in Wuhan, China. JAMA. 2020;323(11):1061-9. doi: 10.1001/jama.2020.1585.

23. Zheng Z, Peng F, Xu B, Zhao J, Liu H, Peng J, et al. Risk factors of critical \& mortal COVID-19 cases: a systematic literature review and meta-analysis. J Infect. 2020;81(2):e16-e25. doi: 10.1016/j.jinf.2020.04.021.

24. Rod JE, Oviedo-Trespalacios O, Cortes-Ramirez J. A brief-review of the risk factors for COVID-19 severity. Rev Saude Publica. 2020;54:60. doi: 10.11606/s15188787.2020054002481.

25. Zhou F, Yu T, Du R, Fan G, Liu Y, Liu Z, et al. Clinical course and risk factors for mortality of adult inpatients with COVID-19 in Wuhan, China: a retrospective cohort study. Lancet. 2020;395(10229):1054-62. doi: 10.1016/s01406736(20)30566-3.

26. Pan F, Ye T, Sun P, Gui S, Liang B, Li L, et al. Time course of lung changes at chest CT during recovery from coronavirus disease 2019 (COVID-19). Radiology. 2020;295(3):715-21. doi: 10.1148/radiol.2020200370.

27. Chen J, Qi T, Liu L, Ling Y, Qian Z, Li T, et al. Clinical progression of patients with COVID-19 in Shanghai, China. J Infect. 2020;80(5):e1-e6. doi: 10.1016/j.jinf.2020.03.004.

28. Besharat S, Malekpour Alamda N, Dadashzadeh N, Talaie R, Mousavi SS, Barzegar A, et al. Clinical and demographic characteristics of patients with COVID-19 who died in Modarres hospital. Open Access Maced J Med Sci. 2020;8(T1):144-9. doi: 10.3889/oamjms.2020.5013.

29. Dalan R, Bornstein SR, El-Armouche A, Rodionov RN, Markov A, Wielockx B, et al. The ACE-2 in COVID-19: foe or friend? Horm Metab Res. 2020;52(5):257-63. doi: 10.1055/a-11550501. 